\title{
The Research on the Influential Factors of Migrant Workers' Satisfaction of Vocational Training
}

\author{
Qinglan Luo ${ }^{1, a}$, Yifen Kuang ${ }^{1, b}$ and Chunyan Wang ${ }^{1, c, ~ *}$ \\ ${ }^{1}$ College of Business Administration, Jilin Engineering Normal University, Changchun, China \\ asunny203@126.com, ${ }^{\mathrm{b}} 1120595326 @ q q . c o m,{ }^{\mathrm{c}} 541012329 @ q q . c o m$ \\ * The corresponding author
}

\begin{abstract}
Keywords: Migrant workers; Vocational training; Customer satisfaction; Perceived quality; Perceived value
\end{abstract}

\begin{abstract}
Vocational training is one of the most important ways to improve the skill of migrant workers. Firstly, this paper constructs a theoretical model of the migrant workers' satisfaction of vocational training. Secondly, the descriptive statistical analysis, reliability and validity testing were made by using SPSS 18.0 and AMOS 17.0 for 370 valid questionnaires. Through regression analysis, we found that the migrant workers perceived quality and the perceived value have the significant effect on their satisfaction. The perceived value plays the intermediation role between the migrant workers' perceived quality and their satisfaction. Therefore, the key to improve the migrant worker' satisfaction is to increase their perceived quality and the perceived value.
\end{abstract}

\section{Introduction}

The sustainable development of social economy can't be separated from the high quality human resources in a country or region. It has become the important strategic decision to develop human resources and improve the skill of workers through vocational training. Today more and more enterprises have the higher requirement about the workers' quality. Whether the new or the experienced employees who are willing to participate the vocational training to improve their skill. The vocational training is paid more attention as a "sunrise industry". As we all know the more capital enter into it, the fiercer competition will be. Vocational training industry faces not only opportunities but also challenges. The vocational training institutions which meet the requirements of the training staff would obtain the competition advantages in the future.

Generally, the training result is regarded as the evaluation standard of the vocational training industry, which focuses on educational qualifications and passing rate of training staff. But it usually ignores the training staff's feelings and satisfaction in the training process. As the requirement of improving the service quality and competition aggravation, more and more vocational training institution provide high training services for their training staff and focus on their experience and feeling. They arrange reasonable courses and appropriate training content for them. Therefore, the training staff's satisfaction would be one of the important indicators in the quality evaluation of vocational training industry.

\section{Related Concept and Model Construction}

Related Concept. Vocational training is the planned and systematic training activities which improve the workers' knowledge, skills, attitudes and behavior [1]. Customer's satisfaction is the customer's psychological state which comes from the customer's consumption feelings comparing with their expectations to the enterprise's product [2]. The perceived quality refers to the customer's service expectation comparing with the actual perceived performance [3]. When the actual perceived performance is better than the customer's service expectation, customer's perceived quality is high, vice versa. The perceived value refers to customer's perception of the benefits by adding the price and 
quality. It is measured by comparing the quality under the same prices or the price under the same service [4].

Model Construction. According to the study of customer's satisfaction model and the characteristic of the vocational training, this paper constructs the theory model of the migrant workers' satisfaction from two aspects which are the perceived quality and the perceived value. A number of research showed that the training staff perceived quality has the positive effect on the their satisfaction (Brady \& Cronin, 2001; Li Zhu, 2016) [5] [6]. Fornell etc. (1996) confirmed that the higher customer perceived value, the more customer feel satisfaction [7]. Garver \& Wimatns(2009) found that the customer perceived value is helpful to improve the customer's satisfaction [8]. Xiao-gang zhou (2014) found that the customer perceived quality is the basis of the value evaluation, and the customers perceived quality have the effect on the perceived value [9]. It meant that the perceived value plays the intermediary role between the perceived quality and the customer's satisfaction. According to the literature discussed above, making the following assumptions:

H1: Perceived quality has a positive effect on the migrant workers' satisfaction of vocational training.

H2: Perceived quality has a positive effect on the perceived value.

H3: Perceived value has a positive effect on the migrant workers' satisfaction of vocational training.

H4: Perceived value plays the partial intermediary role between the perceived quality and the migrant workers' satisfaction of vocational training.

Theoretical model about migrant workers' satisfactory of vocational training is shown in Fig. 1.

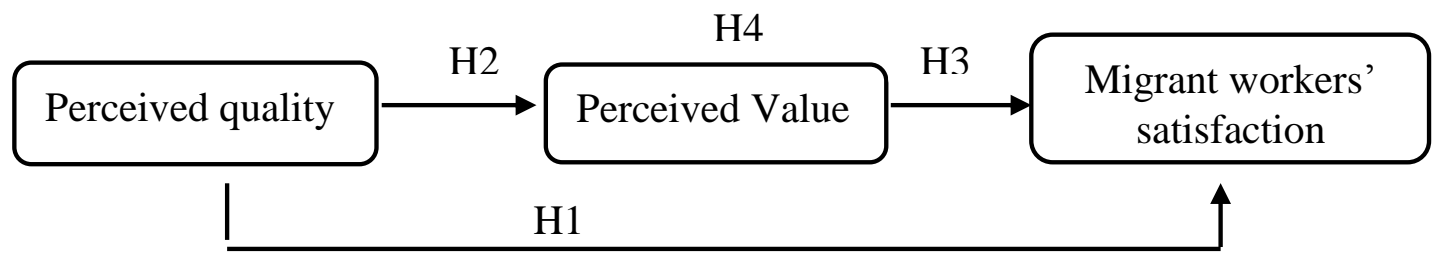

Figure 1. Theoretical model

\section{Data analysis and Hypothesis Testing}

Questionnaire Collection. We collected the data through questionnaires (paper questionnaires and electronic questionnaires) to practitioners who are migrant workers. In order to verify the theory model and hypothesis, program instructors distributed 400 questionnaires to respondents. A total of 380 questionnaires were returned, after deleting records of invalid questionnaires, a total of 370 questionnaires remained representing the effective response rate of $92.5 \%$. Descriptive statistics of valid samples are shown in Table 1 and Table 2.

Table 1 Distribution feature of samples

\begin{tabular}{c|c|c|c}
\hline Statistical variables & Category & Frequency & Percent \\
\hline \multirow{2}{*}{ Sex } & Male & 238 & $64.32 \%$ \\
& female & 132 & $35.68 \%$ \\
\hline \multirow{3}{*}{ Age } & Under 18 years old & 6 & $1.62 \%$ \\
& $18-22$ years old & 105 & $28.38 \%$ \\
& $22-30$ years old & 186 & $50.27 \%$ \\
& More than 30 years old & 73 & $19.73 \%$ \\
\hline \multirow{2}{*}{ Education } & Primary school & 35 & $9.46 \%$ \\
level & Junior high school & 46 & $12.43 \%$ \\
& High school & 218 & $58.92 \%$ \\
& Junior college & 45 & $12.16 \%$ \\
& Bachelor degree or above & 26 & $7.03 \%$ \\
\hline \multirow{2}{*}{ Income level } & Unmarried & 157 & $42.43 \%$ \\
& Married & 178 & $48.11 \%$ \\
& Marital misfortune & 35 & $9.46 \%$ \\
\hline
\end{tabular}


Table 2 Descriptive statistics of latent variables

\begin{tabular}{c|c|c|c}
\hline Latent variable & Sample volume & Mean value & Standard deviation \\
\hline Perceived quality & 370 & 3.628 & 0.798 \\
\hline Perceived value & 370 & 3.561 & 0.865 \\
\hline Migrant worker's satisfactory & 370 & 3.889 & 0.942 \\
\hline
\end{tabular}

Reliability Analysis. Questionnaire reliability is analyzed by using SPSS18.0. Each variable scale Cronbach' $s \alpha$ is more than 0.7. It showed that the scale were more reliable [10]. Each scale reliability value is shown in Table 3.

Table 3 Reliability of the scale

\begin{tabular}{c|c|c}
\hline Constructs & items & Cronbach's $\boldsymbol{\alpha}$ \\
\hline Migrant worker' satisfaction & 10 & 0.867 \\
\hline Perceived quality & 8 & 0.798 \\
\hline Perceived value & 4 & 0.881 \\
\hline
\end{tabular}

Validity Analysis. Questionnaire validity is analyzed by using Amos 17.0. All the indicators of the three factors model meet the requirements, as shown in Table 4.

Table 4 Construct validity of the scale

\begin{tabular}{c|c|c|c|c|c|c}
\hline Model & NFI & CFI & GFI & RMR & RMSEA & AIC \\
\hline three factors model & 0.865 & 0.927 & 0.867 & 0.069 & 0.063 & 432.857 \\
\hline
\end{tabular}

Hypothesis Testing. The hypotheses are tested by regression analysis to verify whether the conclusions are true or false. First, the perceived quality is regarded as the independent variable, the perceived value and the migrant workers' satisfaction as the dependent variables; second, the perceived value is regarded as the independent variable, and the migrant workers' satisfaction as the dependent variable; third, the perceived quality and the perceived value are regarded as the independent variables, the migrant workers' satisfaction as the dependent variable. The results are shown in Table 5.

Table 5 Regression of variable

\begin{tabular}{c|c|c|c}
\hline \multirow{2}{*}{ Variable } & \multicolumn{2}{c}{ Dependent variable } \\
\cline { 3 - 4 } $\begin{array}{c}\text { Independent } \\
\text { variable }\end{array}$ & Perceived quality & $0.384 * * *$ & $0.378^{* * *}$ \\
\hline \multirow{2}{*}{ Statistical } & F value & $28.768 * * *$ & Pigrant worker' satisfaction \\
magnitude & R2 & 0.294 & $29.563 * * *$ \\
& Adjust R2 & 0.321 & 0.254 \\
Independent & Perceived value & & 0.362 \\
variable & F value & & $0.366^{* * *}$ \\
\hline \multirow{2}{*}{ Statistical } & R2 & & $27.320^{* * *}$ \\
magnitude & Adjust R2 & & 0.198 \\
& Perceived quality & & 0.173 \\
\hline Independent & Perceived value & & $0.344 * * *$ \\
variable & F value & & $0.331 * * *$ \\
\hline \multirow{2}{*}{ Statistical } & R2 & & 0.259 \\
magnitude & Adjust R2 & & 0.253 \\
\hline
\end{tabular}

Note: $* * *: \mathrm{p}<0.001, * *: \mathrm{p}<0.01, *: \mathrm{p}<0.05$ 
There is the strong correlation among the perceived quality, the perceived value and the migrant worker' satisfaction. Coefficient Pearson is 0.384, 0.378, 0.366 respectively (Sig.<0.001), which indicates that the perceived quality, the perceived value and the migrant worker' satisfaction are closely related to each other. So the $\mathrm{H} 1, \mathrm{H} 2$ and $\mathrm{H} 3$ are all true. When it takes the perceived quality and the perceived value as the independent variables, Coefficient Pearson between the perceived quality and the migrant worker' satisfaction decrease to 0.344 (Sig. $<0.001$ ). So the H4 is also true. The perceived value plays the partial intermediary role between the perceived quality and migrant workers' satisfaction of vocational training. Hypothesis testing conclusions are shown in Table 6.

Table 6 Hypothesis testing conclusion

\begin{tabular}{c|l|c}
\hline Hypothesis & \multicolumn{1}{|c|}{ Contents } & Result \\
\hline H1 & $\begin{array}{l}\text { Perceived quality has a positive impact on the } \\
\text { migrant workers' satisfaction of vocational training. }\end{array}$ & True \\
\hline H2 & $\begin{array}{l}\text { Perceived quality has a positive impact on the } \\
\text { perceived value. }\end{array}$ & True \\
\hline H3 & $\begin{array}{l}\text { Perceived value has a positive impact on the migrant } \\
\text { workers' satisfaction of vocational training. }\end{array}$ & True \\
\hline H4 & $\begin{array}{l}\text { Perceived value plays the partial intermediary role } \\
\text { between the perceived quality and the migrant } \\
\text { workers' satisfaction of vocational training. }\end{array}$ & True \\
\hline
\end{tabular}

\section{Conclusion and Future Expectations}

Discussions. Data analysis and study conclusion mainly include: After the confirmatory factor analysis was carried out by using AMOS 17.0, the three factors were extracted according to each principal components variance contribution rates, consistent with the number of latent variables contained in the model, the general situation of which can be well reflected in the questionnaire.

As can be seen from the regression results, the perceived quality and the perceived value have significant positive effect on the migrant workers'satisfaction of vocational training. Meanwhile, the migrant workers' perceived value plays the partial intermediary role between the perceived quality and the migrant workers' satisfaction of vocational training. Therefore, it is very important to improve the perceived quality and the perceived value for the vocational training institution.

Future Expectations. In this study, we took the migrant workers as research object, but did not do the relevant study to other population groups. Therefore, the further research needed to explore the generality of these findings. And this study doesn't take into account the social economic factors impact on the results. In this paper, we build the theory model about the migrant workers' satisfaction of vocational training; whether this model can be widely used in vocational training industry is still questionable. In different cases or condition the results may be different, so we should eliminate interference factors or control variables in the future research. It is worthy to study deeply the other factors influencing the migrant workers' satisfaction of vocational training.

\section{Acknowledgment}

The authors gratefully acknowledge the support of Jilin Provincial Educational Science Planning Office (Contract NO. GH16386).

\section{References}

[1] K.Y. Zhu, X.B. Lei and B.S. Zhang: Journal of Henan Vacation-Technical Teachers University (Vocational Education Edition), Vol. 11 (2004) No.4, p.8-10.

[2] H. Luo: Popular Science, Vol. 7 (2011) No.1, p.136. 
[3] R.T. Arthur and J.D. Irving: Total Quality Management-Three Steps to Continuous Improvement (Trans Addisorr Wesley, New York 1992).

[4] Y.T. Fang: E-Education Research, Vol. 31 (2013) No.10, p.58-65.

[5] M. Brady and J. Cronin: Journal of Marketing, Vol. 65 (2001 No.3, p.34-49.

[6] L. Zhu. The research on the impact of perceived quality and perceived value on consumer satisfaction of vocational training (MS., Shanxi University of Finance and Economics, China 2016), p.23.

[7] C. Fornell, M.D. Johnson and E.W. Anderson et al.: Journal of Marketing, Vol. 60 (1996) No.4, p.7-18.

[8] M.S. Garver and Z. Williams: Journa1 of Marketing Model of Understanding Management, Vol. 79 (2009) No.1, p.113-132.

[9] X.G. Zhou: JiangXi social sciences, Vol. 35 (2014) No.7, p.35-38.

[10]J.C.Nunnally: Overview of Psychological Measurement (Trans Clinical Diagnosis of Mental Disorders, Springer US 1978) 